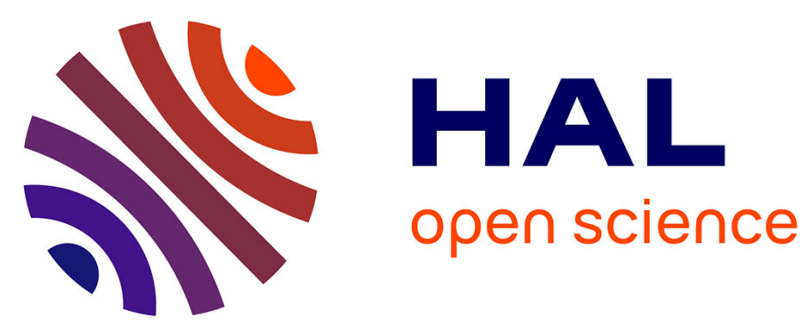

\title{
Magnetic Anisotropy Drives Magnetochiral Dichroism in a Chiral Molecular Helix Probed with Visible Light
}

\author{
Matteo Atzori, Fabio Santanni, Ivan Breslavetz, Kévin Paillot, Andrea \\ Caneschi, Rikken G.L.J.A., Roberta Sessoli, Cyrille Train
}

\section{- To cite this version:}

Matteo Atzori, Fabio Santanni, Ivan Breslavetz, Kévin Paillot, Andrea Caneschi, et al.. Magnetic Anisotropy Drives Magnetochiral Dichroism in a Chiral Molecular Helix Probed with Visible Light. Journal of the American Chemical Society, 2020, 142 (32), pp.13908-13916. 10.1021/jacs.0c06166 . hal-03048340

\author{
HAL Id: hal-03048340 \\ https://hal.science/hal-03048340
}

Submitted on 9 Dec 2020

HAL is a multi-disciplinary open access archive for the deposit and dissemination of scientific research documents, whether they are published or not. The documents may come from teaching and research institutions in France or abroad, or from public or private research centers.
L'archive ouverte pluridisciplinaire HAL, est destinée au dépôt et à la diffusion de documents scientifiques de niveau recherche, publiés ou non, émanant des établissements d'enseignement et de recherche français ou étrangers, des laboratoires publics ou privés. 


\title{
Magnetic Anisotropy drives Magneto-Chiral Dichroism in a Chiral Molecular Helix probed with Visible Light
}

Matteo Atzori, ${ }^{*}, 1$ Fabio Santanni, ${ }^{2}$ Ivan Breslavetz, ${ }^{1}$ Kévin Paillot, ${ }^{1}$ Andrea Caneschi, ${ }^{3}$ Geert L. J. A. Rikken, ${ }^{1}$ Roberta Sessoli*,2 and Cyrille Train*,1

1 Laboratoire National des Champs Magnétiques Intenses (LNCMI), Univ. Grenoble Alpes, INSA Toulouse, Univ. Toulouse Paul Sabatier, EMFL, CNRS, F-38043 Grenoble, France.

2 Dipartimento di Chimica "Ugo Schiff” e INSTM, Università degli Studi di Firenze, Via della Lastruccia 3, I-50019 Sesto Fiorentino (Firenze), Italy

3 Dipartimento di Ingegneria Industriale - DIEF e INSTM, Università degli Studi di Firenze, Via di Santa Marta 3, I-50139 Firenze, Italy

\begin{abstract}
Magneto-Chiral Dichroism (MChD) is a non-reciprocal manifestation of lightmatter interaction that can be observed in chiral magnetized systems. It features a differential absorption of unpolarized light depending on the relative orientation of the magnetic field and the light wavevector and on the absolute configuration of the system. The relevance of this effect for optical readout of magnetic data calls for a complete understanding of the microscopic parameters driving $\mathrm{MChD}$ with an easy-accessible and non-demaging light source, such as visible light. For this purpose, here we report on $\mathrm{MChD}$ detected with visible light on a chiral magnetic helix formulated as $\left[\mathrm{Mn}^{\mathrm{III}}(\right.$ cyclam $\left.)\left(\mathrm{SO}_{4}\right)\right] \mathrm{ClO}_{4} \cdot \mathrm{H}_{2} \mathrm{O}$ (cyclam $=1,4,8,11$ tetraazacyclotetradecane) featuring antiferromagnetically coupled anisotropic $\mathrm{Mn}^{\mathrm{III}}$ ions. Alternate current susceptibility measurements revealed the existence of a single-chain magnet behavior hidden below the canted antiferromagnetism $\left(T_{N}=5.8 \mathrm{~K}\right)$ already evidenced by direct current magnetometry. A detailed analysis of the optical absorption gives access to the value of the zero-field splitting parameter $D\left(2.9 \mathrm{~cm}^{-1}\right)$, which quantifies the magnetic anisotropy of the $\mathrm{Mn}^{\mathrm{III}}$ centers. Below the magnetic ordering temperature of the material, the MChD spectra exhibit intense absolute configuration dependent $\mathrm{MChD}$ signals reaching record values of ca. $12 \%$ of the absorbed intensity for the two electronic transitions most influenced by the spinorbit coupling of the $\mathrm{Mn}^{\mathrm{III}}$ ion. These findings set a clear route towards the design and preparation of highly MChD-responsive molecular materials.
\end{abstract}




\section{INTRODUCTION}

Chirality and its numerous consequences and applications are an ever-fascinating field of research for both chemists and physicists. In this respect, the interplay between chiral objects and magnetic fields has been recognized as a crucial topic since the $19^{\text {th }}$ century. ${ }^{1}$ Nonetheless, it came to theoretical maturity only in the 1980s with the prediction of Magneto-Chiral Dichroism (MChD), ${ }^{2,3}$ a manifestation of an enantioselective light-matter interaction resulting in a differential absorption $(\Delta \mathrm{A})$ of unpolarized light in magnetic field that depends on the relative orientation of the light wavevector $\boldsymbol{k}$ and the magnetic field $\boldsymbol{B}$ pseudovector. ${ }^{4} \mathrm{MChD}$ does not require a circularly polarized light source to be observed, as needed for natural circular dichroism (NCD) and magnetic circular dichroism (MCD), because its ability to interact enantioselectively with chiral systems derives from the true chirality, as defined by L. D. Barron in 1986, originating in this specific case from the combination of an unpolarized light beam and a magnetic field oriented parallel or antiparallel with respect to each others..$^{5-7}$ Magneto-Chiral effects involving the mutual interaction of magnetic fields and unpolarized light were first experimentally demonstrated in the 1990s in light emission (luminescence), ${ }^{4}$ absorption, ${ }^{8}$ and refraction (Magneto-Chiral Birefringence) ${ }^{3,9}$ Since then, $\mathrm{MChD}$ has been observed in specific systems for frequencies ranging from microwaves ${ }^{10}$ to hard X-rays, ${ }^{11,12}$ underlining the universality of this effect. ${ }^{13-15}$

Nonetheless, apparently contradicting results appeared about the microscopic origins of this effect: the studies with X-ray light indicate that the existence of an orbital contribution to the magnetic moment of the absorber is a crucial feature to observe $\mathrm{MChD},{ }^{11}$ whereas, with visible light $\mathrm{MChD}$ is also observed for metal ions with weak orbital moments, such as copper(II), ${ }^{16}$ chromium(III) ${ }^{17,18}$ or manganese(II). ${ }^{19}$ It is thus of utmost importance to unravel the origins of $\mathrm{MChD}$ for the electronic transitions falling in the visible range of the electromagnetic spectrum. Understanding the microscopic parameters that govern $\mathrm{MChD}$ in the visible will enable the design of new materials with a strong enough effect for optical readout of magnetic data with a non-damaging and easy accessible light source, as recently envisioned but not yet demonstrated. ${ }^{20,21}$ Furthermore, because MChD can generate enantiomeric enrichments in photochemical reactions, ${ }^{22}$ it has been proposed as one of the possible initiation mechanisms for the origin of the homochirality of life on Earth.,23 However, the intimate connection between $\mathrm{MChD}$ and the generation of high enantiomeric enrichments remains scarcely explored. ${ }^{18}$ 
Molecule-based materials are particularly appropriate for in-depth investigations of $\mathrm{MChD}$ because different metal ions and coordination geometeries can be investigated and crystallization in chiral space groups can be achieved in different ways, from spontaneous resolution to enantioselective self-assembly. ${ }^{13,24}$

To investigate the effect of orbital contributions to $\mathrm{MChD}$ probed through visible light,

we have identified $\left[\mathrm{Mn}^{\mathrm{III}}(\right.$ cyclam $\left.)\left(\mathrm{SO}_{4}\right)\right] \mathrm{ClO}_{4} \cdot \mathrm{H}_{2} \mathrm{O} \quad$ (1) $\quad($ cyclam $=1,4,7,11-$ tetraazacyclotetradecane) as a good candidate. ${ }^{25}$ In this system, spontaneous resolution leads to the formation of chiral coordination helices where $\mathrm{Mn}^{\mathrm{III}}$ ions are bridged by sulfate anions. Upon a tetragonal elongation of the coordination sphere induced by Jahn-Teller distortion of the octahedral high-spin $\mathrm{Mn}^{\mathrm{III}}$ centers, magnetic anisotropy appears due to the orbital contribution of the excited states. This source of magnetic anisotropy gives birth to original magnetic behaviors such as single-molecule magnets ${ }^{26}$ or single-chain magnets. ${ }^{27}$ In $\mathbf{1}$, the combination of single-ion magnetic anisotropy of $\mathrm{Mn}^{\mathrm{III}}$ and antiferromagnetic interactions along the coordination chain results in a three-dimensional weak ferromagnetism below a critical temperature of $5.8 \mathrm{~K}$. Notably, the material magnetization shows a strong magnetic response when the magnetic field is aligned along the $a$ crystallographic axis and a weak magnetization along the $b$ and $c$ axes. Here we will recall the main structural features and magnetic properties of $\mathbf{1},{ }^{25}$ then a complete alternate current $(a c)$ magnetic susceptibility study, a full analysis of the optical spectrum recorded at low temperature, and a quantitative interpretation of the $\mathrm{MChD}$ spectrum will be presented to give a complete overview of this system and question the influence of magnetic anisotropy on MChD strenght.

\section{RESULTS AND DISCUSSION}

Material Preparation. Compound 1 was prepared according to what was already reported in the literature by reaction of trans-[Mn(cyclam $\left.)\left(\mathrm{H}_{2} \mathrm{O}\right)_{2}\right]\left(\mathrm{CF}_{3} \mathrm{SO}_{3}\right) \cdot \mathrm{H}_{2} \mathrm{O}$ and sulfate anions in presence of sodium perchlorate. ${ }^{25}$ The axial aqua ligands of the $\mathrm{Mn}^{\mathrm{III}}$ precursors are replaced by sulfate anions that act as bridging ligands between $[\mathrm{Mn}(\mathrm{cyclam})]^{3+}$ moieties. This results in one-dimensional (1D) infinite chains of $\left[\mathrm{Mn}(\text { cyclam })\left(\mathrm{SO}_{4}\right)\right]^{+}$cationic units whose charge is counterbalanced by a perchlorate anion per formula unit. ${ }^{25}$ Slow evaporation of diluted solutions of 1 allows obtaining single crystals with good optical quality, a key feature for quantitative evaluation of $\mathrm{MChD}$. 
Crystal Structure. The molecular and crystal structure of $\mathbf{1}$ was already described. ${ }^{25}$ However, it is important to remind here the most salient features in view of the description of the magnetooptical measurements.

The molecular structure of $\mathbf{1}$ is shown in Figure 1. Each $\mathrm{Mn}^{\mathrm{III}}$ ion is coordinated in the equatorial plane by the four $\mathrm{N}$ donor atoms of the cyclam ligand. The $\mathrm{Mn}-\mathrm{N}$ bond distances are in the 2.031-2.052 $\AA$ range, while the two sulfate anions that coordinate $\mathrm{Mn}^{\mathrm{III}}$ in the axial positions provide $\mathrm{Mn}-\mathrm{O}$ bond distances of $2.142(1)$ and $2.145(1) \AA$. Overall, $\mathrm{Mn}^{\mathrm{III}}$ is in a tetragonally elongated octahedral coordination environment due to the Jahn-Teller effect, ${ }^{28}$ which is typical of octahedrally coordinated high spin $d^{4}$ ions showing unevenly occupied $\mathrm{e}_{\mathrm{g}}$ orbitals. The symmetry of the $\mathrm{Mn}^{\mathrm{III}}$ centers is thus best represented by the $D_{4 h}$ point group. ${ }^{29}$ Accordingly, the immediate environment of the metal ion is not chiral, but at the second coordination sphere level, the different relative orientation of the two sulfate anions that coordinates $\mathrm{Mn}^{\mathrm{III}}$ on the axial axis breaks the inversion symmetry at the metal center, a characteristic that should promote the observation of MChD. ${ }^{13}$

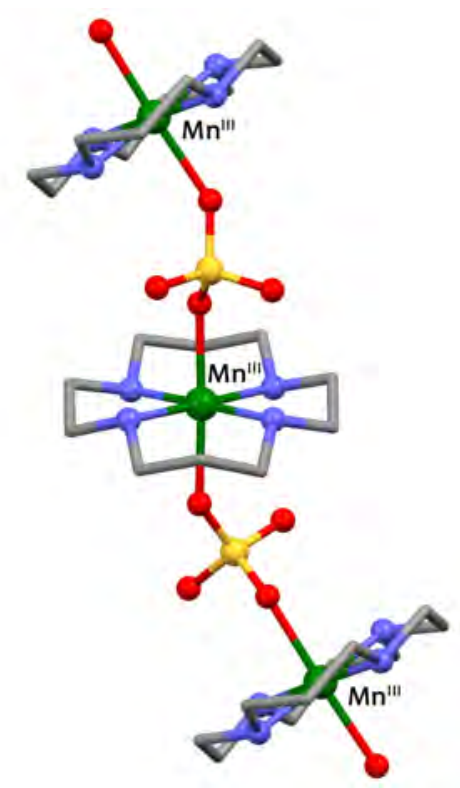

Figure 1. Molecular structure of 1. Perchlorate anions, crystallization water molecules and $\mathrm{H}$ atoms are omitted for graphical clarity. Color code: green, Mn; light blue, N; red, O; yellow, S; gray, C.

Each sulfate anion maintains its tetrahedral shape and bridges two $\mathrm{Mn}^{\mathrm{III}}$ centers. As in the case of $\alpha$ - $\mathrm{NiSO}_{4} \cdot 6 \mathrm{H}_{2} \mathrm{O}$, the first compound where $\mathrm{MChD}$ has been investigated through light absorption, ${ }^{8}$ the non-centrosymmetric tetrahedral shape of the anion favors the helical shape of 1D infinite chains along the $b$ crystallographic axis (Figure 1), resulting in the crystallization in a chiral orthorhombic space group, $P 2{ }_{1} 2{ }_{1} 2_{1}$. The $\mathrm{Mn}-\mathrm{Mn}$ intrachain distance is $6.362 \AA$, and the tilt angle $\varphi$ between the tetragonal axis and the $b$ axis is ca. $15.6^{\circ}$. With a twofold screw 
axis, the pitch of the helix is equal to the crystallographic parameter along $b$, that is $12.584 \AA$. Because the molecular building blocks are not chiral, clockwise and anticlockwise helical arrangements are equally possible. Thus, the system crystallizes as a conglomerate, a 50:50 mixture of enantiopure crystals showing clockwise and anticlockwise helical arrangements, respectively. The structure is stabilized by $\mathrm{H}$-bonds between the $\mathrm{H}$ atoms of the cyclam ligand and the non-coordinating oxygens of the sulfate anions, as well as with crystallization water molecules and perchlorate anions (Figure S1). The shortest M-M inter-chain distance is 8.552 $\AA$.

Magnetic Properties. As for the structural description, let us recall the main magnetic features of 1 before presenting the new results obtained by ac magnetic susceptibility measurements.

From room temperature to ca. $6 \mathrm{~K}$, the thermal dependence of the $d c$ magnetic susceptibility has the typical shape observed for antiferromagnetically coupled 1D $S=2$ systems. ${ }^{25}$ Contrasting with a pure $1 \mathrm{D}$ behavior, the magnetic susceptibility abruptly increases at ca. $6 \mathrm{~K}$ indicating the onset of canted antiferromagnetic arrangement of the magnetic moments (Figure 2). The canting is due to the axial magnetic anisotropy of the $\mathrm{Mn}^{\mathrm{III}}$ ions combined with the tilt angle between the tetragonal axis of the manganese centers and the orientation of the chain along the $b$ crystallographic axis.
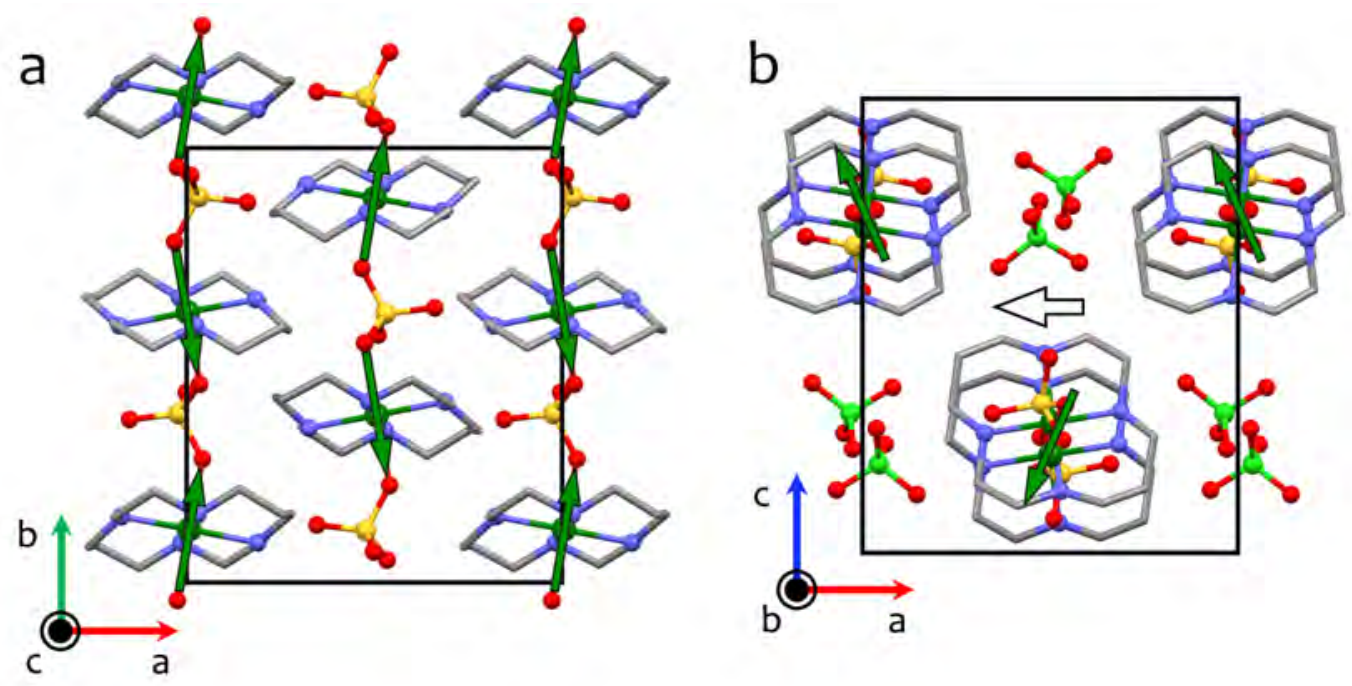

Figure 2. View of a portion of the crystal structure of $\mathbf{1}$ in the $a b$ (a) and $a c$ (b) crystallographic planes. Green arrows schematically represent the arrangement of the magnetic moments in the crystal structure. The black empty arrow in panel $\mathrm{b}$ shows the resulting overall magnetic moment oriented along the $a$ crystallographic axis. Crystallization water molecules and hydrogen atoms are omitted for graphical clarity. In panel a perchlorate anions are also omitted. Color codes: green, Mn; light blue, N; red, O; yellow, S; gray, C. 
The differences observed in the Zero Field Cooled (ZFC) and Field Cooled (FC) temperaturedependent magnetization measurements performed on an oriented single crystal of 1 along the three crystallographic axes (Figure S2a) clearly highlight the huge magnetic anisotropy of $\mathbf{1}$. Magnetization measurements as a function of the applied magnetic field $\boldsymbol{B}$ performed at $T=2.0$ $\mathrm{K}$ along the three crystallographic axes strengthen these conclusions (Figure S2b). ${ }^{25}$ Along the $a$ axis, the magnetization increases rapidly at very low applied fields and then increases with a linear behavior above ca. $0.5 \mathrm{~T}$. Along $b$ the magnetization is almost suppressed and at $6.0 \mathrm{~T}$ only represents ca. $10 \%$ of the value observed at the same field along the $a$ axis. Along $c$, the magnetization shows an intermediate behavior with respect the $a \| \boldsymbol{B}$ and $b \| \boldsymbol{B}$ cases, showing a slow increase up to ca. $0.5 \mathrm{~T}$, then a rapid increase up to $1.0 \mathrm{~T}$, and then a linear increase similar to that along $a$.

This behavior was semi-quantitatively rationalized by considering both the intrachain antiferromagnetic interaction between the $\mathrm{Mn}^{\mathrm{III}}$ centers considering the dual action of the exchange interaction, quantified by $J$, and the magnetic anisotropy of $\mathrm{Mn}^{\mathrm{III}}$ ions, quantified by the axial zero-field splitting parameter $D .^{20}$ The two parameters appeared to have the same magnitude, ca. $3 \mathrm{~cm}^{-1} \cdot{ }^{25}$ Because the magnetic anisotropy easy-axis of the $\mathrm{Mn}^{\mathrm{III}}$ ions is slightly tilted from the $b$ axis, the intrachain antiferromagnetic interaction almost completely cancels the component of the magnetization along $b$ (Figure $2 \mathrm{a}$ ) and very high fields are needed to overcome this interaction. Given that the chains are generated by a 21 screw axis along $b$, the uncompensated magnetic moment has components only along $a$ and $c$. The long-range order observed below $6 \mathrm{~K}$ appears to be governed by antiferromagnetic interactions mediated by the hydrogen-bonds network connecting units related by the $2{ }_{1}$ screw axis along $a$. The antiferromagnetic interaction between the main components cancels the contribution along $c$, leaving a weak-ferromagnetic component along $a$ (Figure $2 \mathrm{~b}$ ), which accounts for ca. $5.8 \%$ of the full magnetization of a $S=2$ system.

Uniaxial anisotropy within 1D-coupled systems can lead to Single-Chain Magnet (SCM) behavior, that is, to a slow relaxation of the magnetization of molecular origin. ${ }^{27}$ Herein, we have performed $a c$ susceptibility measurements to have access to the dynamics of the magnetization to unravel long-range magnetic ordering phenomena and a potential SCM behavior.

The investigation was undertaken on a microcrystalline sample of $\mathbf{1}$ between $2.0 \mathrm{~K}$ and $9.0 \mathrm{~K}$ in the frequency range $10 \mathrm{~Hz}-10000 \mathrm{~Hz}$. Measurements were performed at $d c$ magnetic fields values of 0 and 10 Oe. Because of the extreme sensibility of magnetic phase transitions to the applied magnetic field, each measurement was rigorously performed by cooling the 
sample in zero $d c$ field and by using an oscillating magnetic field of 3 Oe. The variation of the real $\chi^{\prime}$, and imaginary $\chi^{\prime \prime}$, components of the molar magnetic susceptibility for $\mathbf{1}$ as a function of the frequency of the oscillating magnetic field and the temperature, are reported in Figures $\mathrm{S} 3$ and S4 for $\boldsymbol{B}_{d c}=0$ Oe and 10 Oe, respectively. Figure 3 reports a bidimensional projection of a $3 \mathrm{D}$ plot showing the variation of $\chi^{\prime}$ and $\chi^{\prime \prime}$ as a function of both temperature and frequency in zero static field.

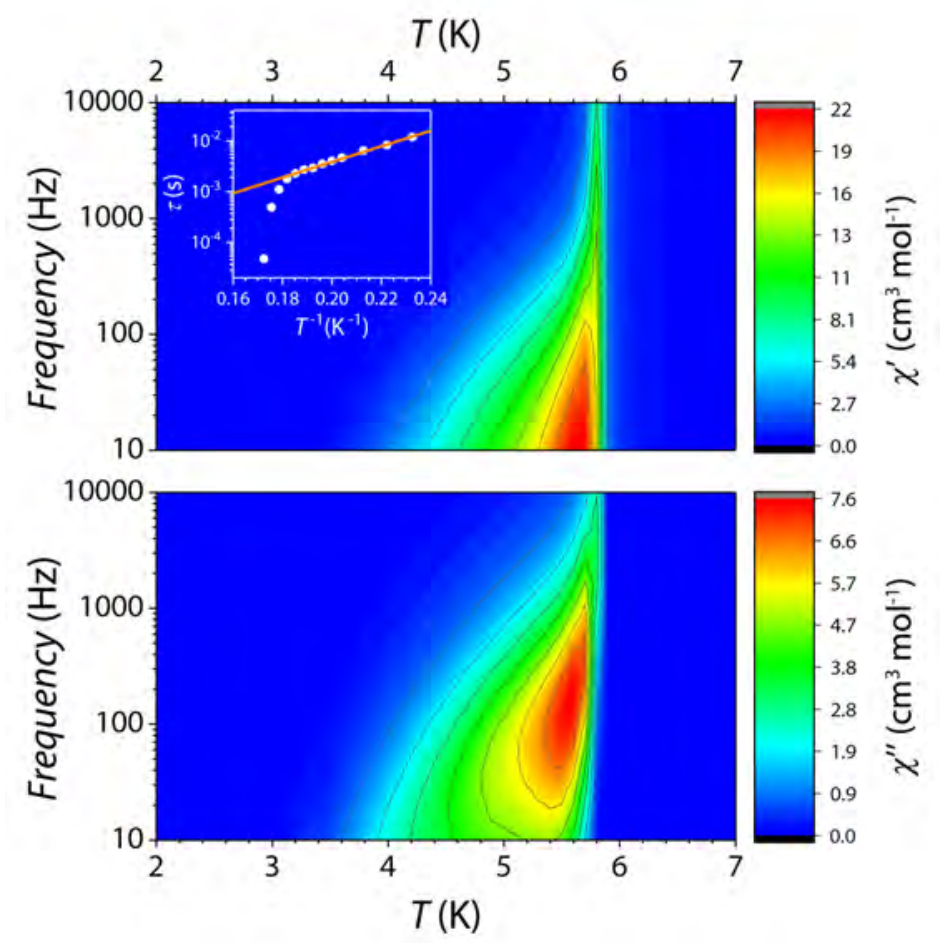

Figure 3. 2D projection of the 3D plot showing the temperature $T(\mathrm{~K})$, and frequency $(\mathrm{Hz})$ variation of $\chi^{\prime}\left(\mathrm{cm}^{3} \mathrm{~mol}^{-1}\right)$ (top) and $\chi^{\prime \prime}\left(\mathrm{cm}^{3} \mathrm{~mol}^{-1}\right)$ (bottom) at $\boldsymbol{B}_{d c}=0$ Oe. Inset shows the temperature dependence $(1 / T)$ of the relaxation times $\tau$ and the Arrhenius-like fits in the dynamic regime (5.6-4.3 $\mathrm{K}$, orange line).

When the temperature is lowered to $5.8 \mathrm{~K}$, which corresponds to the magnetic ordering temperature identified through $d c$ measurements, a sudden increase, almost frequency independent is observed for both components of the ac magnetic susceptibility (Figure 3). Such a behavior is typical for a transition to a magnetically ordered state. By further lowering the temperature, a frequency dependent shoulder is clearly observed (Figure 3b), which is reminiscent of SCM behavior. The relaxation time values were extracted by fitting the isothermal frequency dependence of the ac susceptibility data (Figure S3 and S4) with a generalized Debye model. ${ }^{30}$ The obtained parameters for the two different values of the $d c$ magnetic field are reported in Tables S1 and S2. An Arrhenius-like model of the form $\tau=$ $\tau_{0} \exp \left(\Delta E / k_{B} T\right)$ was used to fit the data at zero field (inset to Figure 3). Between $5.8 \mathrm{~K}$ and 5.6 
K the relaxation time shows a temperature dependence that is associated to a high energy barrier $A E^{\prime} / k_{B}=509 \pm 148 \mathrm{~K}$ and an extremely small pre-exponential factor $\tau \theta^{\prime}=8.36 \cdot 10^{-32} \mathrm{~s}$. These values are in the typical range of those observed for long-range ordered magnetic systems rather than for SCMs. The extracted energy barrier, $\Delta E / k_{B}=36 \pm 1 \mathrm{~K}$, is comparable to the values observed in Mn ${ }^{\mathrm{III}}$-based SCMs. ${ }^{31-33}$ The characteristic time $\tau_{0}=3.14 \pm 0.76 \cdot 10^{-6} \mathrm{~s}$ is higher than what generally found for SCMs in the infinite-size regime. ${ }^{31,32}$

The application of a static weak magnetic field $(10 \mathrm{Oe})$ affects the $a c$ susceptibility mainly around the phase transition, with the relaxation times that slightly increase (Figure S5). More relevant is the decrease in the slow relaxing susceptibility, defined as $\chi_{T}-\chi_{\mathrm{S}}$, where $\chi_{T}$ and $\chi S$ are the isothermal and the adiabatic susceptibility, i.e. for $v \rightarrow 0$ and $v \rightarrow \infty$ limits, respectively. Around $T=5.6 \mathrm{~K}$ the reduction of $\chi_{T}-\chi_{\mathrm{S}}$ reaches up to $70 \%$ but it decreases to less than $20 \%$ at $4.5 \mathrm{~K}$ (Figure S6).

The coexistence of of two regimes characterized by different frequency dependence of $\chi_{a c}$ has already been observed in 1D systems long-range ordering transitions. ${ }^{34}$ It can be explained as the result of the competition between magnetic interactions of different magnitude present in these compounds. A smaller but multidirectional exchange interaction between the chains is responsible for the long-range magnetic ordering, providing almost frequency independent peaks. The stronger monodirectional interaction within each chain is involved in the process of magnetization reversal, ${ }^{35}$ and the SCM behavior can be observed superimposed to the critical anomaly. ${ }^{34,36}$ The need to overcome the stronger intrachain exchange interaction appears at the origin of extremely high coercivity observed in some chain-based materials. ${ }^{27,37-}$ 39

It is interesting to compare the low temperature dynamics with that expected for this $\mathrm{Mn}^{\mathrm{III}}$ chain in the absence of interchain interactions. Taking into account the model developed for canted antiferromagnetic chains, ${ }^{27}$ the activation energy is given by

$$
\Delta E=4 S^{2}|J| \cos 2 \varphi+|D| S^{2}
$$

On the basis of the values of $J, D$, and $\varphi$ previously estimated, equation (2) provides $\Delta E=76$ $\mathrm{K}$, which is the double of the experimental one. This is coherent with the fact that equation (2) provides an upper limit for $\Delta E$ as it assumes that the magnetic anisotropy is much stronger than the exchange interaction, ${ }^{40,41}$ a condition which is not satisfied here. The small activation energy restricts the observation of SCM behavior to the low temperature regime, that is, below the magnetic ordering. 
Visible Light Absorption Spectroscopy. To get insights on the electronic transitions that characterize 1, single crystals of ca. $0.3 \mathrm{~mm} \times 0.8 \mathrm{~mm} \times 1 \mathrm{~mm}$ (Figure S7) were used to record absorption spectra in transmission mode along the $a$ crystallographic axis as a function of the temperature (294-4.0 K) in the 420-1000 nm spectral window. The $a$ crystallographic axis has the highest magnetic response and is also the direction that can be most easily probed through optical and magneto-optical measurements because single crystals preferentially grow along the $b$ and $c$ axes.

The temperature variations of the absorption coefficient is reported in Figure 4, while Figure S8 shows a comparison between the spectra recorded at 293 and $4.0 \mathrm{~K}$.

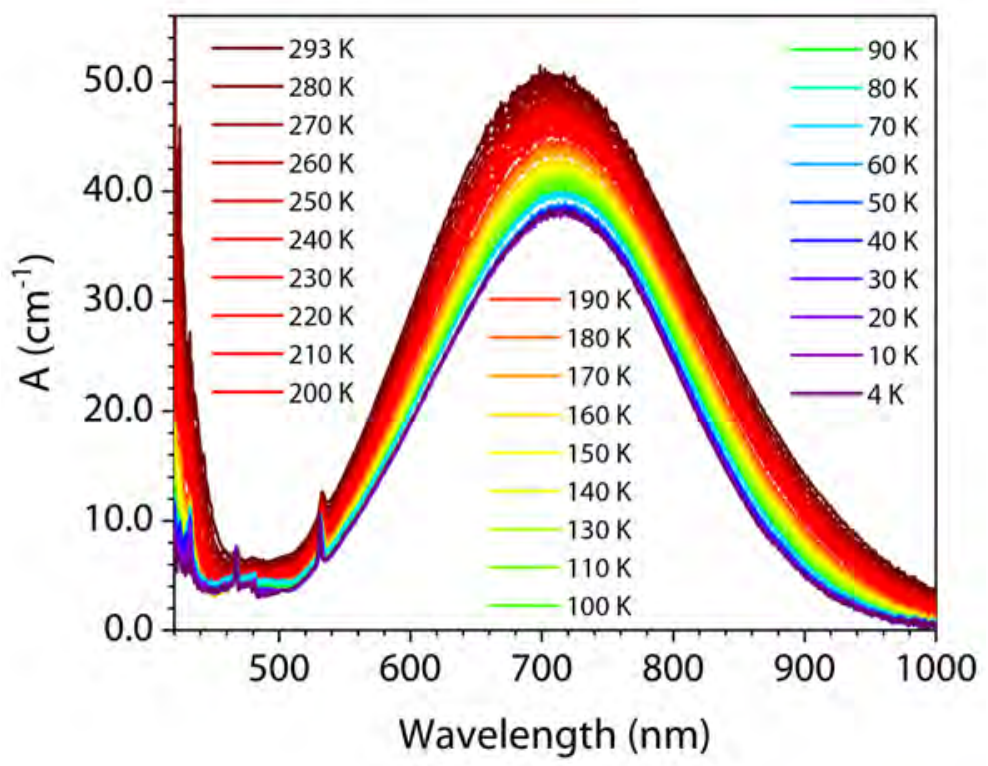

Figure 4. Temperature variation (see legend) of the absorption coefficient A $\left(\mathrm{cm}^{-1}\right)$ for a single crystal of $\mathbf{1}$ with light propagation vector $\boldsymbol{k}$ parallel to the $a$ crystallographic axis.

The electronic spectrum at room temperature shows one intense and broad absorption band centered at $\lambda=705 \mathrm{~nm}$ and fine-structured peaks between 420 and $540 \mathrm{~nm}$. By lowering the temperature, the intensity of the band centered at $\lambda=705 \mathrm{~nm}$ decreases and shift towards lower energies $(\lambda=715 \mathrm{~nm}$ at $4.0 \mathrm{~K})$ while the fine-structured peaks became sharper and well visible. A well-defined sharp peak is observed at $\lambda=530 \mathrm{~nm}$, which is slightly blue shifted at $4.0 \mathrm{~K}$ with respect to the room temperature value. A fine-structured absorption that consists in two peaks, one sharper and one broader, are observed at $\lambda=480$ and $467 \mathrm{~nm}$. The energies of these two peaks are essentially temperature independent. Finally, a peak at $\lambda=432 \mathrm{~nm}$ is observed. This peak is slightly blue shifted at $4.0 \mathrm{~K}$ with respect to the room temperature absorption, as the one at $\lambda=530 \mathrm{~nm}$. It should be also mentioned that the region between 
$420-450 \mathrm{~nm}$ is at the limit of the spectrometer resolution, and the intensity and fine-structure of this absorption peak can be affected by this instrumental limitation.

High-spin $\mathrm{Mn}^{\mathrm{III}}$ has four unpaired $d$ electrons and a ground state electronic configuration $\mathrm{t}_{2 g}{ }^{3} \mathrm{e}_{g}{ }^{1}$ in an octahedral crystal field $\left(O_{h}\right)$. Accordingly, it can show a single spin-allowed $d-d$ transition between the ground quintet state ${ }^{5} \mathrm{E}_{2 \mathrm{~g}}$ and the first excited quintet state ${ }^{5} \mathrm{~T}_{2 \mathrm{~g}}$ deriving from the splitting of the ${ }^{5} \mathrm{D}$ term symbol. ${ }^{42}$ However, the Jahn-Teller distortion through tetragonal elongation, which is typical of octahedral high-spin $d^{4}$ complexes, including compound $\mathbf{1}$, breaks the symmetry of the $\mathrm{t}_{2 g}{ }^{3} \mathrm{e}_{g}{ }^{1}$ configuration to stabilize one unpaired electron in a non-degenerate $\mathrm{a}_{1 g}\left(d_{z^{2}}\right)$ orbital level. ${ }^{28}$ The resulting $d$-orbital diagram (Figure S9) corresponds to the quintet ground state configuration ${ }^{5} \mathrm{~B}_{1 \mathrm{~g}}{ }^{43}$ This implies that three spinallowed $d-d$ transitions are possible for $\mathrm{Mn}^{\mathrm{III}}$ in $D_{4 h}$ symmetry corresponding to the electronic excitations from singly occupied $d_{z^{2}}, d_{x y}$, and $d_{x z}$ or $d_{y z}$ orbitals to the unoccupied $d_{x^{2}-y^{2}}$ orbital. In spectroscopic terms, this corresponds to the electronic transitions ${ }^{5} \mathrm{~A}_{1 \mathrm{~g}} \leftarrow{ }^{5} \mathrm{~B}_{1 \mathrm{~g}},{ }^{5} \mathrm{~B}_{2 \mathrm{~g}} \leftarrow{ }^{5} \mathrm{~B}_{1 \mathrm{~g}}$ and ${ }^{5} \mathrm{E}_{\mathrm{g}} \leftarrow{ }^{5} \mathrm{~B}_{1 \mathrm{~g}}$ respectively, the latter being double degenerate (Figure S9). ${ }^{44}$ The energy associated to the ${ }^{5} \mathrm{~B}_{2 \mathrm{~g}} \leftarrow{ }^{5} \mathrm{~B}_{1 \mathrm{~g}}$ corresponds to $\Delta_{O}$, while the energy associated to the ${ }^{5} \mathrm{~A}_{1 \mathrm{~g}} \leftarrow{ }^{5} \mathrm{~B}_{1 \mathrm{~g}}$ transition provides the value of the tetragonal splitting $\Delta_{e}$ of the parent ${ }^{5} \mathrm{E}_{2 \mathrm{~g}}$ state. ${ }^{43,44}$ The value of the tetragonal splitting, $\Delta_{t}$, of the parent ${ }^{5} \mathrm{~T}_{2 \mathrm{~g}}$ term can be instead obtained through the difference between the energy of the ${ }^{5} \mathrm{E}_{\mathrm{g}} \leftarrow{ }^{5} \mathrm{~B}_{1 \mathrm{~g}}$ and ${ }^{5} \mathrm{~B}_{2 \mathrm{~g}} \leftarrow{ }^{5} \mathrm{~B}_{1 \mathrm{~g}}$ transitions. ${ }^{44}$

Spin-forbidden $d$ - $d$ transitions are also possible for $\mathrm{Mn}^{\mathrm{III}}$ in $D_{4 h}$ configuration within the energy range probed. By taking into account the Tanabe-Sugano diagram for a $d^{4}$ ion in $O_{h}$ symmetry, ${ }^{45}$ the first excited triplet state ${ }^{3} \mathrm{~T}_{1 \mathrm{~g}}$, deriving from the splitting of the ${ }^{3} \mathrm{H}$ term symbol, has an energy comparable to the spin-allowed transitions derived from the splitting of the ${ }^{5} \mathrm{~T}_{2 \mathrm{~g}}$ state. Considering that under Jahn-Teller elongation the ${ }^{3} \mathrm{~T}_{1 \mathrm{~g}}$ state will split into ${ }^{3} \mathrm{~A}_{2 \mathrm{~g}}$ and ${ }^{3} \mathrm{E}_{\mathrm{g}}$ states, two additional spin-forbidden electronic transitions, ${ }^{3} \mathrm{~A}_{2 \mathrm{~g}} \leftarrow{ }^{5} \mathrm{~B}_{1 \mathrm{~g}}$ and ${ }^{3} \mathrm{E}_{\mathrm{g}} \leftarrow{ }^{5} \mathrm{~B}_{1 \mathrm{~g}}$, can be expected.

Based on this analysis and by referring to the low temperature spectrum, the lowest energy absorption band centered at $\lambda=715 \mathrm{~nm}\left(\Delta_{e}=14000 \mathrm{~cm}^{-1}\right)$ is assigned to the lowest energy spinallowed transition ${ }^{5} \mathrm{~A}_{1 \mathrm{~g}} \leftarrow{ }^{5} \mathrm{~B}_{1 \mathrm{~g}}$, the peak at $\lambda=530 \mathrm{~nm}\left(\Delta_{O}=18800 \mathrm{~cm}^{-1}\right)$ is assigned to the ${ }^{5} \mathrm{~B}_{2 \mathrm{~g}} \leftarrow{ }^{5} \mathrm{~B}_{1 \mathrm{~g}}$ transition, and the peak at $\lambda=432 \mathrm{~nm}\left(23000 \mathrm{~cm}^{-1}\right)$ to the ${ }^{5} \mathrm{E}_{\mathrm{g}} \leftarrow{ }^{5} \mathrm{~B}_{1 \mathrm{~g}}$ transition. The $\Delta_{t}$ value is ca. $4200 \mathrm{~cm}^{-1}$. The peaks at $\lambda=467 \mathrm{~nm}\left(21400 \mathrm{~cm}^{-1}\right)$ and $481 \mathrm{~nm}\left(20800 \mathrm{~cm}^{-1}\right)$ are assigned to the ${ }^{3} \mathrm{~A}_{2 \mathrm{~g}} \leftarrow{ }^{5} \mathrm{~B}_{1 \mathrm{~g}}$ and ${ }^{3} \mathrm{E}_{\mathrm{g}} \leftarrow{ }^{5} \mathrm{~B}_{1 \mathrm{~g}}$ spin-forbidden transitions respectively (Table $1)$. 
Table 1. Summary of spectral bands assignment with nature of the electronic transitions involved (electronic terms and $d$-orbitals) and spin-orbit coupling character of each of them. $\lambda=\zeta / 2 S$, where $\zeta$ the spin-orbit coupling parameter of the free ion and $S$ the spin ground state.

\begin{tabular}{ccccc}
\hline $\boldsymbol{\lambda}(\mathbf{n m})$ & $\boldsymbol{\Delta E}\left(\boldsymbol{c m}^{-1}\right)$ & Electronic Transition & d-orbitals involved & Spin-orbit coupling character \\
\hline 432 & 23000 & ${ }^{5} \mathrm{E}_{\mathrm{g}} \leftarrow{ }^{5} \mathrm{~B}_{1 \mathrm{~g}}$ & $d_{x-y 2} \leftarrow d_{x z, y z}$ & $\lambda^{2}$ \\
467 & 21400 & ${ }^{3} \mathrm{~A}_{2 \mathrm{~g}} \leftarrow{ }^{5} \mathrm{~B}_{1 \mathrm{~g}}$ & $d_{x y} \leftarrow d_{z^{2}}$ & 0 \\
481 & 20800 & ${ }^{3} \mathrm{E}_{\mathrm{g}} \leftarrow{ }^{5} \mathrm{~B}_{1 \mathrm{~g}}$ & $d_{x z, y z} \leftarrow d_{z^{2}}$ & $4 \lambda^{2}$ \\
530 & 18000 & ${ }^{5} \mathrm{~B}_{2 g} \leftarrow{ }^{5} \mathrm{~B}_{1 \mathrm{~g}}$ & $d_{x 2-y 2} \leftarrow d_{x y}$ & $4 \lambda^{2}$ \\
715 & 14000 & ${ }^{5} \mathrm{~A}_{1 \mathrm{~g}} \leftarrow{ }^{5} \mathrm{~B}_{1 \mathrm{~g}}$ & $d_{x-y 2} \leftarrow d_{z^{2}}$ & 0 \\
\hline
\end{tabular}

All these energy values are in very good agreement with the literature data for both molecular coordination compounds or inorganic materials based on $\mathrm{Mn}^{\mathrm{III}}$ ions featuring a tetragonally elongated octahedron coordination geometry. $43,46,47$

The assignation reported above is also supported by another crucial feature, the intensity and broadness of the lowest energy band centered at $\lambda=715 \mathrm{~nm}$. One can argue that the intensity of this spin-allowed absorption should be similar to that of the other spin-allowed transitions. However, it should be reminded that it results from a transition between two components of the ${ }^{5} \mathrm{E}_{2 \mathrm{~g}}$ state split by the $D_{4 h}$ distortion, while the other two transitions involve one of the two ${ }^{5} \mathrm{~T}_{2 \mathrm{~g}}$ state components. This broadening has been explained as a result of a dynamical tetragonal distortion, a modulation of the bond distances along the tetragonal axis..$^{47}$ By strongly affecting the energy of the $d_{z^{2}}$ and $d_{x^{2}-y^{2}}$ orbitals, a wide range of energies is available to promote this transition. Indeed, in most of $\mathrm{Mn}^{\mathrm{III}}$ compounds, the lowest energy absorption band is usually very broad. ${ }^{47}$

The well-resolved visible spectrum allows to estimate the magnetic anisotropy of the $\mathrm{Mn}^{\mathrm{III}}$ ion taking into account the spin-orbit coupling contribution arising from the admixing of non-degenerate orbital states with excited states. According to well-established relations for tetragonally elongated $d^{4}$ ions, ${ }^{48-51}$ the value of the axial zero field splitting parameter $D$ can be obtained through the following equation:

$$
D=\lambda^{2}\left[-\frac{4}{\Delta E\left({ }^{5} \mathrm{~B}_{2 g} \leftarrow{ }^{5} \mathrm{~B}_{1 g}\right)}+\frac{1}{\Delta E\left({ }^{5} \mathrm{E}_{g} \leftarrow{ }^{5} \mathrm{~B}_{1 g}\right)}-\frac{4}{\Delta E\left({ }^{3} \mathrm{E}_{g} \leftarrow{ }^{5} \mathrm{~B}_{1 g}\right)}\right]
$$

where $\lambda=\zeta / 2 S$, and $\zeta$ the spin-orbit coupling parameter of the free ion. Assuming $\zeta=360$ $\mathrm{cm}^{-1}, 52$ the calculated value of $D$ is $2.9 \mathrm{~cm}^{-1}$, which is in good agreement with the value 
estimated from previous magnetic studies. ${ }^{25}$ It is interesting to notice that the ${ }^{5} \mathrm{~A}_{1 \mathrm{~g}}$ and ${ }^{3} \mathrm{~A}_{2 \mathrm{~g}}$ states do not contribute because the matrix elements of the spin-orbit coupling are zero for their related transitions (Table 1). ${ }^{48,49}$

Magneto-Chiral Dichroism. MChD measurements were performed in transmission mode along the $a$ crystallographic axis of two enantiomeric crystals of $\mathbf{1}$, denoted hereafter $\mathbf{1}-\boldsymbol{A}$ and 1-B. The MChD spectra of the same single crystals used for absorption measurements were analyzed.

Multiple sharp MChD signals originating from the difference in the absorption under magnetic field of the electronic transitions at $\lambda=530,481,467$ and $432 \mathrm{~nm}$ are observed (Figure 5). On the contrary, the large absorption band centered at $\lambda=715 \mathrm{~nm}$ does not show any detectable MChD (Figure S10). Measurements performed in the same conditions for $\mathbf{1}-\boldsymbol{A}$ and 1-B provides signals of opposite signs resulting in perfect mirror image spectra. The signals for 1- $\boldsymbol{A}$ are positive for the electronic transitions at $\lambda=432,467$, and $481 \mathrm{~nm}$, while that at $\lambda=530$ $\mathrm{nm}$ is negative. It can be also noted that, although MChD signals of both absorption band-shape (similarly to the Faraday B and C terms in MCD) $)^{53,54}$ and $1^{\text {st }}$ derivative band-shape (Faraday A terms in MCD) $)^{53,54}$ can be in principle observed, ${ }^{4} \mathbf{1}$ shows only absorption band-shaped signals. A brief description of Faraday A, B and C terms in MCD spectroscopy is reported in the Supplementary Information. 

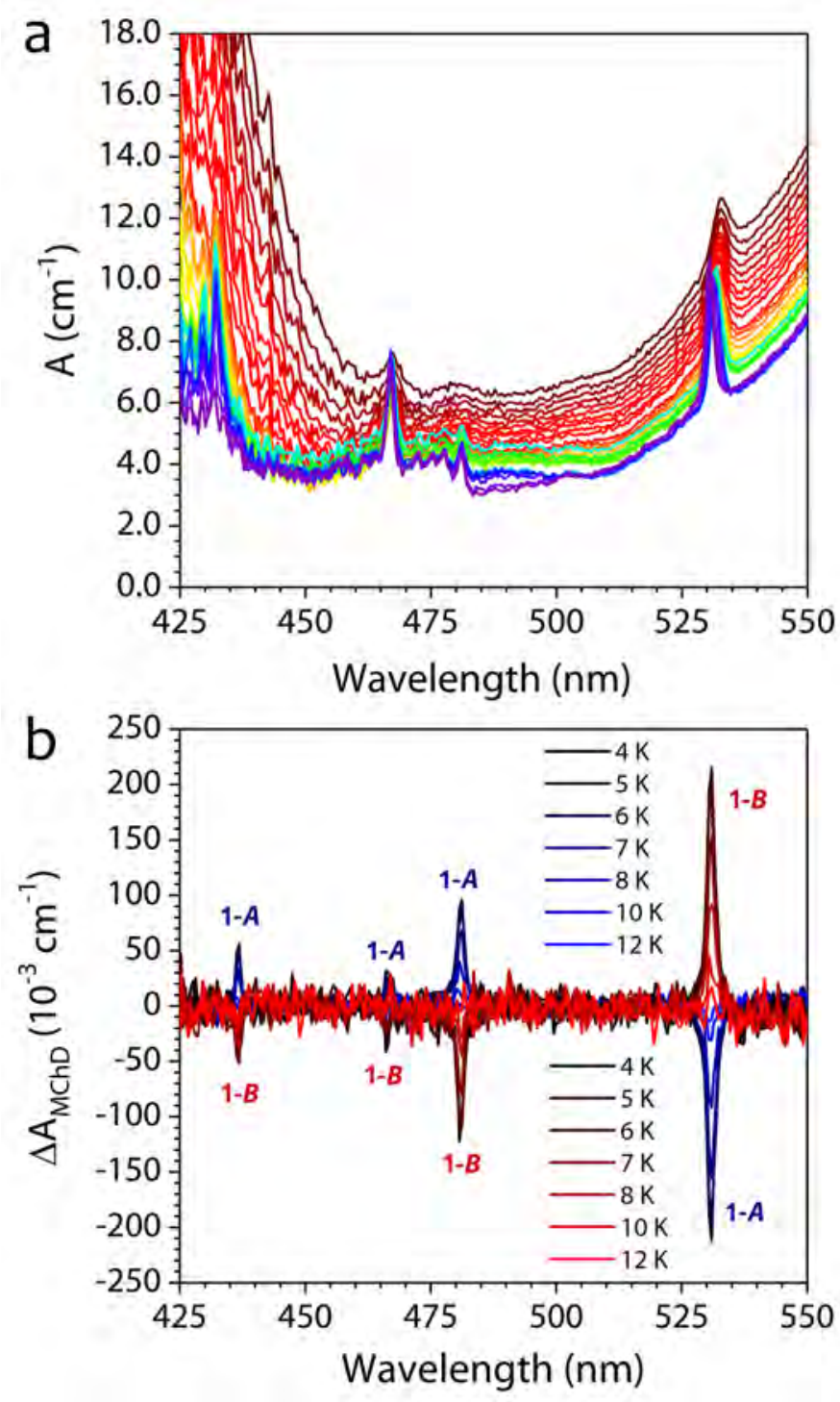

Figure 5. Temperature variation (see legends) of the absorption coefficient $A\left(\mathrm{~cm}^{-1}\right)$ (a) and the $\triangle A_{M C h D}$ (b) recorded on single crystals of $\mathbf{1}-\boldsymbol{A}$ and $\mathbf{1 - B}$ with the light propagation vector $\boldsymbol{k}$ and the magnetic field $\boldsymbol{B}$ oriented along to the $a$ crystallographic axis.

Following the interpretation of the absorption spectra, it appears that the MChD signal with the highest absolute intensity is associated to the spin-allowed ${ }^{5} \mathrm{~B}_{2 \mathrm{~g}} \leftarrow{ }^{5} \mathrm{~B}_{1 \mathrm{~g}}$ transition, while the second most intense MChD signal corresponds to the spin-forbidden ${ }^{3} \mathrm{E}_{\mathrm{g}} \leftarrow{ }^{5} \mathrm{~B}_{1 \mathrm{~g}}$, which has the weakest absorption of the series.

By comparing the intensity of these two MChD signals recorded at $T=4.0 \mathrm{~K}$ with those recently associated to $\mathrm{Mn}^{\mathrm{II}}$ in a chiral $\mathrm{Mn}^{\mathrm{II}} \mathrm{Cr}^{\mathrm{III}}$ molecular magnet showing ferrimagnetic ordering, ${ }^{19}$ their $\triangle \mathrm{A}_{\mathrm{MChD}}$ are ca. 2 orders of magnitude more intense.

The temperature dependence of $\Delta \mathrm{A}_{\mathrm{MChD}}$ for the most intense signal $(\lambda=530 \mathrm{~nm})$ was compared to compound $\mathbf{1}$ magnetization measured at the same field used for $\mathrm{MChD}$ 
experiments (Figure 6a). The superimposition of the two curves confirms that the enhancement of the MChD signal when decreasing the temperature follows the spontaneous magnetization of the material, as previously observed in ferromagnetic or ferrimagnetic molecular magnets. ${ }^{17,19}$
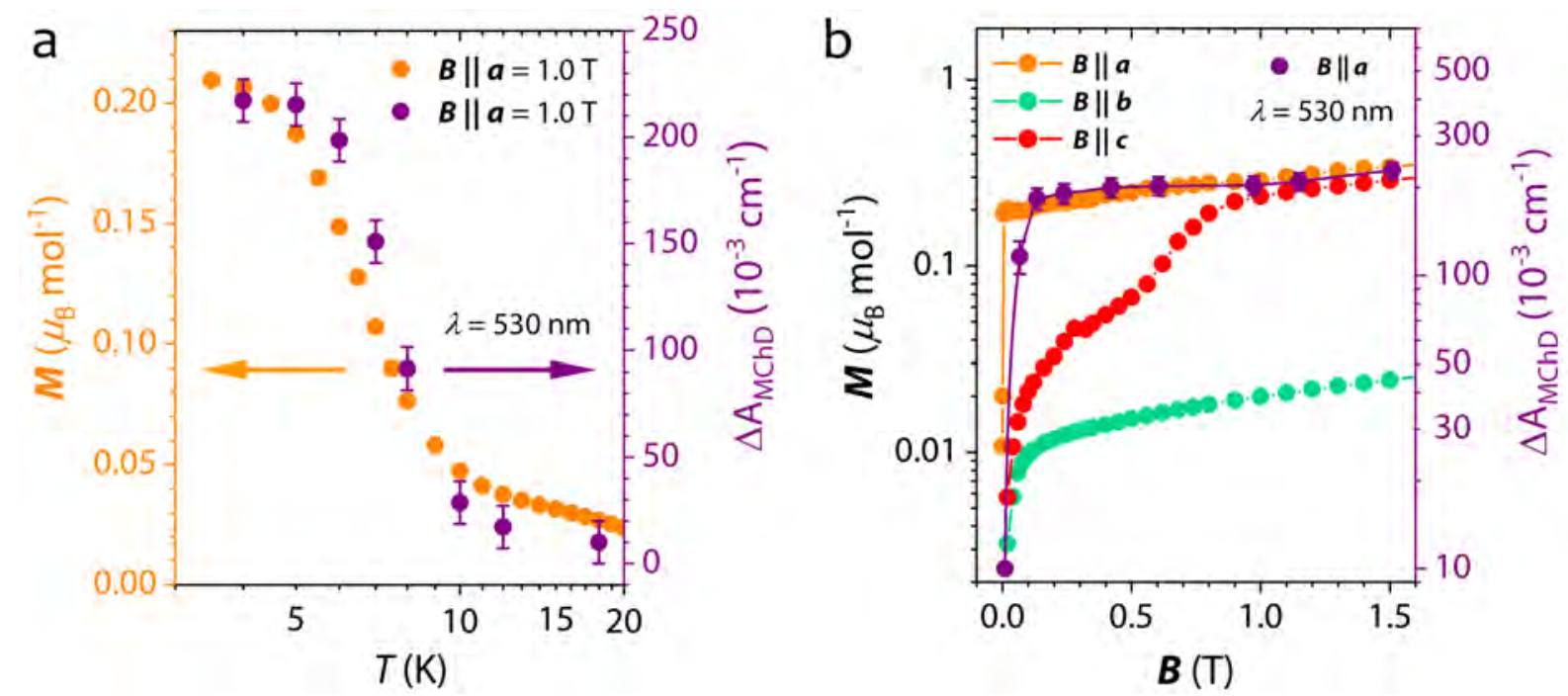

Figure 6. Temperature (a) and magnetic field (b) dependence of the $\Delta \mathrm{A}_{\mathrm{MChD}}$ signal $(\lambda=530 \mathrm{~nm})(\boldsymbol{B}=$ $1.0 \mathrm{~T}, T=4.0 \mathrm{~K}$, respectively) for $\mathbf{1 - B}$ compared to field cooled magnetization data. Semi-log graphs are used for panels a and $\mathrm{b}$ to better highlight the correspondence between magneto-optical and magnetic data. Lines in panel $b$ are not fits and should be considered only guides for the eyes.

This close relationship between the magnetization of the sample and its MChD signal is definitely supported by the MChD measured along the $a$ axis, which superimposes with the magnetization measured along $a$ (Figure 6b).

These findings give some clues about the mechanism at the basis of MChD in the visible range. First, in accordance with previous measurements in this spectral range, intense and sharp MChD signals can be easily detected. ${ }^{17,19}$ Second, despite the absence of chirality at the metal centers, intense MChD signals associated with specific electronic transitions of the metal ions are present. This confirms the possibility of exploiting the non-local character of chirality to observe strong MChD signals, although the proximity with chiral centers can drastically increase their intensity. ${ }^{19}$ Third, and most important, the increase by two orders of magnitude between the magneto-chiral optical response of anisotropic $\mathrm{Mn}^{\mathrm{III}}$ and isotropic $\mathrm{Mn}^{\mathrm{II}}$ despite the weak ferromagnetism of the former, hence the low value of the overall magnetization even along $a$, indicates how MChD is sensitive to an orbital contribution to the magnetic moment of the absorbing center.

To quantify the MChD, we exploited the anisotropy factor $g_{\mathrm{MChD}},{ }^{8}$ which is defined as 


$$
g_{\mathrm{MChD}}=\frac{(\mathrm{A}(\boldsymbol{B} \uparrow)-\mathrm{A}(\boldsymbol{B} \downarrow))}{1 / 2(\mathrm{~A}(\boldsymbol{B} \uparrow)+\mathrm{A}(\boldsymbol{B} \downarrow))}=2 \frac{\Delta \mathrm{A}_{\mathrm{MChD}}}{\mathrm{A}}
$$

where the effective absorption coefficients A of the involved transitions are obtained by spectra deconvolution analysis (Figure S11). This allows an estimation of $g_{\mathrm{MChD}}$ for each observed MChD signal according to equation (4) without the spurious contribution of superimposed absorption bands that are not intrinsically involved in the phenomenon (Table 2).

Table 2. Summary of the $\left|\Delta \mathrm{A}_{\mathrm{MChD}}\right|$ and absorption coefficients obtained through visible light absorption spectroscopy with $\left(\left|\Delta \mathrm{A}_{\mathrm{MChD}}\right|\right)$ and without (A) applied alternate magnetic field on a single crystal of compound 1-B $(T=4.0 \mathrm{~K}, \boldsymbol{B}=1 \mathrm{~T})$. The absolute values of the MChD anisotropy factor, $g_{\mathrm{MChD}}$, are calculated through equation (4).

\begin{tabular}{cccccc}
\hline $\boldsymbol{\lambda}(\mathbf{n m})$ & $\begin{array}{c}\text { Electronic } \\
\text { Transition }\end{array}$ & $|\Delta \mathbf{A M C h D}|\left(\mathbf{c m}^{-\mathbf{1}} \mathbf{T}^{-\mathbf{1}}\right)$ & $\mathbf{A}\left(\mathbf{c m}^{-\mathbf{1}}\right)$ & $\boldsymbol{g}_{\mathbf{M C h D}}$ & Spin-orbit coupling character \\
\hline 432 & ${ }^{5} \mathrm{E}_{\mathrm{g}} \leftarrow{ }^{5} \mathrm{~B}_{1 \mathrm{~g}}$ & $0.06(1)$ & $1.5(5)$ & $0.080(5)$ & $\lambda^{2}$ \\
467 & ${ }^{3} \mathrm{~A}_{2 \mathrm{~g}} \leftarrow{ }^{5} \mathrm{~B}_{1 \mathrm{~g}}$ & $0.03(1)$ & $3.6(5)$ & $0.017(5)$ & 0 \\
481 & ${ }^{3} \mathrm{E}_{\mathrm{g}} \leftarrow{ }^{5} \mathrm{~B}_{1 \mathrm{~g}}$ & $0.09(1)$ & $1.4(5)$ & $0.13(5)$ & $4 \lambda^{2}$ \\
530 & ${ }^{5} \mathrm{~B}_{2 \mathrm{~g}} \leftarrow{ }^{5} \mathrm{~B}_{1 \mathrm{~g}}$ & $0.21(1)$ & $3.8(5)$ & $0.11(5)$ & $4 \lambda^{2}$ \\
715 & ${ }^{5} \mathrm{~A}_{1 \mathrm{~g}} \leftarrow{ }^{5} \mathrm{~B}_{1 \mathrm{~g}}$ & 0 & $38.0(5)$ & 0 & 0 \\
\hline
\end{tabular}

The comparison between the value of $g_{\mathrm{MChD}}$ and the spin-orbit coupling character for a given transition is striking: weak or undetectable $\mathrm{MChD}$ is observed for those transitions that involve, in first approximation, zero $<\alpha\left|\mathrm{L}_{\mathrm{x}, \mathrm{y}, \mathrm{z}}\right| \beta>$ matrix elements, while intense signals are observed for those with strong spin-orbit coupling character. Among the spin-allowed transitions, the intensity of the MChD signals (Table 2 and Figure 5) is also in agreement with the relative (1:4) spin-orbit contribution to the axial zero-field splitting parameter $D$ calculated by second-order perturbation theory (equation 3). Interestingly, the change in sign of the MChD signal of the different transitions reflects the different sign of their contributions to the magnetic anisotropy. Among the spin-forbidden transitions, that associated to a non-zero $<\alpha\left|\mathrm{L}_{\mathrm{x}, \mathrm{y}, \mathrm{z}}\right| \beta>$ matrix element, thanks to its very low intensity in absorption, has the strongest $\mathrm{g}_{\mathrm{MChD}}$ of the whole series. This is in agreement with the high spin-orbit coupling character of this transition $\left(4 \lambda^{2}\right)$ that provides a $\mathrm{g}_{\mathrm{MChD}}$ comparable to that of the electronic transition at $\lambda=530 \mathrm{~nm}$, which is characterized by the same spin-orbit coupling contribution. In turn, the signal at $\lambda=481 \mathrm{~nm}$ yields a value of $g_{\mathrm{MChD}}=0.13(5)(T=4.0 \mathrm{~K}, \boldsymbol{B}=1.0 \mathrm{~T})$. This is one order of magnitude higher than that recently observed for a spin-forbidden $\mathrm{Mn}^{\mathrm{II}}$ electronic transition $\left(g_{\mathrm{MChD}}=0.012(5)\right)$ in a ferrimagnetically ordered molecular magnet at the same temperature and same applied 
magnetic field. ${ }^{19}$ Such a high value is observed despite the fact that, at $1.0 \mathrm{~T}$, the magnetization of $\mathbf{1}$ is only a small fraction (ca. 5.8\%) of the saturation magnetization for an $S=2$ ground spin state system, whereas $\left[\mathrm{Mn}^{\mathrm{II}}(X-p n \mathrm{H})\left(\mathrm{H}_{2} \mathrm{O}\right)\right]\left[\mathrm{Cr}^{\mathrm{III}}(\mathrm{CN})_{6}\right] \cdot \mathrm{H}_{2} \mathrm{O}$ was fully saturated. The proportionality of MChD to the bulk magnetization thus suggests that even higher values of $g_{\mathrm{MChD}}$ should be observed for magnetically saturated $\mathrm{Mn}^{\mathrm{III}}$ systems.

The determination of the $g_{\mathrm{MChD}}$ for the five transitions observed in the visible spectrum of 1 establishes the crucial role of orbital contributions to MChD strength as observed in the hard X-ray region. ${ }^{11}$ Moreover, since only spin-orbit coupling active transitions exhibit high values of $g_{\mathrm{MChD}}$, this mechanism appears as a fundamental ingredient to observe MChD of strong intensity in the visible range.

\section{CONCLUSIONS}

In conclusion, we have reported a complete magneto-optical study of a chiral molecular helix based on anisotropic $\mathrm{Mn}^{\mathrm{III}}$ ions to probe the role of spin-orbit coupling into the intensity of MChD signals associated to specific electronic transitions induced by visible light. The magnetic analysis through alternate current susceptometry has evidenced a Single-Chain Magnet behavior hidden below the long range canted antiferromagnetic order previously evidenced. A combined comprehensive study of the absorption and MChD spectra has shown record values of $g_{\mathrm{MChD}}$ anisotropy factors. More importantly, it has clearly identified the central role of spin-orbit coupling to translate orbital magnetism into MChD strength.

Altogether, these results give clear clues to proceed to a rational chemical approach towards the design and the preparation of new chiral molecular magnets showing strong $\mathrm{MChD}$ in the visible: the ideal compound must be a long-range ordered ferromagnet to ensure a high magnetization and comprise highly anisotropic magnetic ions, such as a tetragonally elongated $\mathrm{Mn}^{\mathrm{III}}$, located at the vicinity of the chiral features of the material. A material meeting these requirements is expected to fulfill the fundamental requirement for the readout of magnetic data using MChD. 


\section{EXPERIMENTAL SECTION}

General Remarks. [Mn(cyclam) $\left.\left(\mathrm{SO}_{4}\right)\right] \mathrm{ClO}_{4} \cdot \mathrm{H}_{2} \mathrm{O}$ (1) was prepared by slightly changing what already described ${ }^{25}$ to induce crystallization of $\mathbf{1}$ as large single crystals (see below). trans$\left[\mathrm{Mn}\right.$ (cyclam) $\left.\left(\mathrm{H}_{2} \mathrm{O}\right)_{2}\right]\left(\mathrm{CF}_{3} \mathrm{SO}_{3}\right) \cdot \mathrm{H}_{2} \mathrm{O}$ was prepared accordingly to the literature procedure. ${ }^{55} \mathrm{All}$ other reagents were purchased and used as received.

An attempt to measure the $\mathrm{MChD}$ at the K-edge of Mn using synchrotron radiation was performed, but the crystals were severely damaged by the X-ray beam (Figure S12). This further highlights the more general feasibility of MChD experiments on molecular samples with UVVis-NIR light with respect to the highly energetic hard X-rays.

Materials preparation. An aqueous solution $(0.5 \mathrm{~mL})$ of $\mathrm{Na}_{2} \mathrm{SO}_{4}(0.100 \mathrm{~g}, 0.69 \mathrm{mmol})$ acidified with few drops of $\mathrm{H}_{2} \mathrm{SO}_{4}$ to $\mathrm{pH}<2$ was added dropwise to an aqueous solution (1.5 $\mathrm{mL})$ of trans-[Mn(cyclam) $\left.\left(\mathrm{H}_{2} \mathrm{O}\right)_{2}\right]\left(\mathrm{CF}_{3} \mathrm{SO}_{3}\right) \cdot \mathrm{H}_{2} \mathrm{O}(0.500 \mathrm{~g}, 1.07 \mathrm{mmol})$. An aqueous solution $(1.5 \mathrm{~mL})$ of $\mathrm{NaClO}_{4} \cdot \mathrm{H}_{2} \mathrm{O}(0.200 \mathrm{~g}, 1.38 \mathrm{mmol})$ was then added to the metal complex solution to obtain $\left[\mathrm{Mn}(\right.$ cyclam $\left.)\left(\mathrm{SO}_{4}\right)\right] \mathrm{ClO}_{4} \cdot \mathrm{H}_{2} \mathrm{O}$ as microcrystalline powder. The precipitate was filtered off and washed with a small amount of ethanol (95\%).

Different crystallization techniques were used to obtain single crystals suitable to perform the magneto-optical investigation. The light blue microcrystalline powder of $\mathbf{1}$ was dissolved in a water solution containing $\mathrm{Na}_{2} \mathrm{SO}_{4}, \mathrm{NaClO}_{4}$ and $\mathrm{H}_{2} \mathrm{SO}_{4}$, in more diluted concentration with respect to the quantities indicated above. Alternatively, the synthesis reported above was performed, in the last step, in a 10 times more diluted solution. In both cases, the resulting light blue solutions were filtered on very thin paper filters and then slowly evaporated for several weeks. By varying the ratio between the diameter of the test tubes and the level of the solution inside them, well-shaped light blue elongated rhomboidal crystals of 1 were obtained. Elemental anal. calcd. for $\mathrm{MnN}_{4} \mathrm{C}_{10} \mathrm{H}_{24} \mathrm{O}_{9} \mathrm{SCl}$ : C, $25.73 ; \mathrm{H}, 5.18 ; \mathrm{N}, 12.00$; found: $\mathrm{C}, 25.86 ; \mathrm{H}$, 5.09; N, 12.05. FT-IR ( $\bar{v}_{\max } / \mathrm{cm}^{-1}, \mathrm{KBr}$ pellet): $3424 \mathrm{~m}, 3185 \mathrm{~s}, 3113 \mathrm{~s}, 2974 \mathrm{w}, 2959 \mathrm{w}, 2933 \mathrm{w}$, $2850 \mathrm{~m}, 1633 \mathrm{w}, 1457 \mathrm{~m}, 1426 \mathrm{~m}, 1384 \mathrm{w}, 1315 \mathrm{w}, 1293 \mathrm{w}, 1254 \mathrm{vw}, 1237 \mathrm{vw}, 1120 \mathrm{vs}, 1052 \mathrm{~s}$, $1032 \mathrm{~s}, 999 \mathrm{~s}, 878 \mathrm{~m}, 804 \mathrm{w}, 621 \mathrm{~s}, 544 \mathrm{vw}, 509 \mathrm{w}, 490 \mathrm{w}$.

Characterization. C, H, N analyses were performed with a CHN-S Flash E1112 Thermofinnigan analyzer. FT-IR spectra were performed on $\mathrm{KBr}$ pellets and collected in the $400-4000 \mathrm{~cm}^{-1}$ range with a Thermo Scientific Nicolet iS50 spectrophotometer. 
Single Crystal X-Ray Crystallography. Single crystals were oriented by X-ray diffraction measurements performed with an Oxford Xcalibur PX Ultra - Onyx CCD diffractometer, using an Enhance Ultra X-ray graphite-monochromated $\mathrm{CuK} \alpha$ radiation $(\lambda=1.540 \AA)$. Elongated rhomboidal single crystals were used for direct current magnetization and $\mathrm{MChD}$ measurements. The longest crystal dimension results parallel to the $b$ crystallographic axis, while $a$ and $c$ axes were found orthogonal to the developed faces. As a result of the elongated shape, magnetic measurements were possible along the three crystallographic axes while the optical measurements were only possible with the magnetic field and wavevector parallel to the $a$ crystallographic axis.

Magnetic measurements. Direct Current magnetization measurements were performed in the 2.0-300 K temperature range with an applied magnetic field of $1.0 \mathrm{~T}$ on an oriented single crystal of compound 1 with mass $0.24 \mathrm{mg}$ by using a Quantum Design Magnetic Properties Measurement magnetometer equipped with a Superconducting Quantum Interference Device. Alternate Current susceptibility measurements were performed in the temperature range 2.0 9.0 K on on a microcrystalline sample of $1(28.1 \mathrm{mg})$ by using a Quantum Design Physical Properties Measurement System equipped with a AC susceptometer in the $10 \mathrm{~Hz}-10 \mathrm{kHz}$ frequency range. The microcristalline sample was pressed into a pellet to avoid partial orientation of the crystallites. Magnetization data were corrected for the sample holders previously measured using the same conditions and for the diamagnetic contributions as deduced by using Pascal's constant tables. ${ }^{56}$

Magneto-Chiral Dichroism Spectroscopy. MChD spectra were recorded with a home-made multichannel MChD spectrometer operating in the visible and near infrared spectral window (400-1600 nm) between 4.0 and $300 \mathrm{~K}$ with an alternating magnetic field $\boldsymbol{B}$ up to $\pm 2 \mathrm{~T}$. A detailed description of the measurement apparatus has been reported elsewhere. ${ }^{57} \mathrm{MChD}$ spectra were acquired on various single crystals of compounds $\mathbf{1}$. Those showing a negative MChD signal at $\lambda=530 \mathrm{~nm}$ were referred as $\mathbf{1}-\boldsymbol{A}$ while those with a positive MChD signal at $\lambda=530 \mathrm{~nm}$ as $\mathbf{1}-\boldsymbol{B}$. The samples were mounted on a titanium sample holder over a $0.8 \mathrm{~mm}$ hole diameter centered with respect to a $1.0 \mathrm{~mm}$ diameter collimated beam. Measurements were performed in the 4.0-18 K range with an alternating magnetic field $\boldsymbol{B}= \pm 1 \mathrm{~T}$ and frequency $\Omega$ $=1.5 \mathrm{~Hz}$. MChD spectra as a function of the magnetic field were recorded at $T=4.0 \mathrm{~K}$ for alternating magnetic fields of different amplitudes with a frequency $\Omega=0.04 \mathrm{~Hz}$. The MChD signals were obtained at each temperature/field by recording, on average, 30.000 spectra with 
an integration time, $t_{\text {int }}$ of $5 \mathrm{~ms}$, every $10 \mathrm{~ms}$. Unpolarized light was provided by Thorlabs broadband Tungsten-Halogen (Thorlabs SLS201L) or Light Emitting Diodes (Thorlabs MCWHF2) light sources. The data were collected with a BWTEK Glacier X detector equipped with a thermoelectric cooled sensor operating in the 420-1000 nm spectral region with a resolution of 16 bits. Each spectrum was correlated to a specific magnetic field value by a dual channel digitizer (Picoscope 5000B) acquiring simultaneously triggers from the spectrometer and the magnetic field from a Hall effect sensor placed in proximity of the sample. Data are then post-processed as a synchronous detection with a MatLab routine to obtain a MChD spectrum.

\section{SUPPORTING INFORMATION}

Additional figures and tables as mentioned in the text.

\section{ACKNOWLEDGMENTS}

The French National Research Agency (ANR) is acknowledged for financial support through ChiraMolCo (ANR 15-CE29-0006) and Monafer (ANR-18-CE09-0032) projects. The support of Italian MIUR through the PRIN 2017CR5WCH project is also acknowledged.

\section{AUTHOR INFORMATION}

\section{Corresponding Authors}

*E-mail: matteo.atzori@lncmi.cnrs.fr

*E-mail: roberta.sessoli@unifi.it

*E-mail: cyrille.train@1ncmi.cnrs.fr

\section{REFERENCES}

(1) L. Pasteur. Relation Qui Peut Exister Entre La Forme Crystalline et La Composition Chimique Sur Las Cause de La Polarization Rotatoire. C. R. Acad. Sci. Paris 1848, 26, $535-539$.

(2) Wagnière, G.; Meier, A. The Influence of a Static Magnetic Field on the Absorption Coefficient of a Chiral Molecule. Chem. Phys. Lett. 1982, 93, 78-81.

(3) Barron, L. D.; Vrbancich, J. Magneto-Chiral Birefringence and Dichroism. Mol. Phys. 1984, 51, 715-730.

(4) Rikken, G. L. J. A.; Raupach, E. Observation of Magneto-Chiral Dichroism. Nature 
1997, 390, 493-494.

(5) Barron, L. D. Symmetry and Molecular Chirality. Chem. Soc. Rev. 1986, 15, 189.

(6) Barron, L. D. True and False Chirality and Parity Violation. Chem. Phys. Lett. 1986, 123, $423-427$.

(7) Barron, L. D. True and False Chirality and Absolute Asymmetric Synthesis. J. Am. Chem. Soc. 1986, 108, 5539-5542.

(8) Rikken, G. L. J. A.; Raupach, E. Pure and Cascaded Magnetochiral Anisotropy in Optical Absorption. Phys. Rev. E 1998, 58, 5081-5084.

(9) Kleindienst, P.; Wagnière, G. H. Interferometric Detection of Magnetochiral Birefringence. Chem. Phys. Lett. 1998, 288, 89-97.

(10) Tomita, S.; Sawada, K.; Porokhnyuk, A.; Ueda, T. Direct Observation of Magnetochiral Effects through a Single Metamolecule in Microwave Regions. Phys. Rev. Lett. 2014, 113,235501 .

(11) Sessoli, R.; Boulon, M.-E.; Caneschi, A.; Mannini, M.; Poggini, L.; Wilhelm, F.; Rogalev, A. Strong Magneto-Chiral Dichroism in a Paramagnetic Molecular Helix Observed by Hard X-Rays. Nat. Phys. 2015, 11, 69-74.

(12) Ceolín, M.; Goberna-Ferrón, S.; Galán-Mascarós, J. R. Strong Hard X-Ray Magnetochiral Dichroism in Paramagnetic Enantiopure Molecules. Adv. Mater. 2012, $24,3120-3123$.

(13) Atzori, M.; Rikken, G. L. J. A.; Train, C. Magneto-Chiral Dichroism: A Playground for Molecular Chemists. Chem. - A Eur. J. 2020, DOI:10.1002/chem.202000937.

(14) Ishii, K.; Hattori, S.; Kitagawa, Y. Recent Advances in Studies on the Magneto-Chiral Dichroism of Organic Compounds. Photochem. Photobiol. Sci. 2020, 19, 8-19.

(15) Taniguchi, K.; Nishio, M.; Kishiue, S.; Huang, P.-J.; Kimura, S.; Miyasaka, H. Strong Magnetochiral Dichroism for Visible Light Emission in a Rationally Designed Paramagnetic Enantiopure Molecule. Phys. Rev. Mater. 2019, 3, 045202.

(16) Taniguchi, K.; Kishiue, S.; Kimura, S.; Miyasaka, H. Local-Site Dependency of 
Magneto-Chiral Dichroism in Enantiopure One-Dimensional Copper(II)-Chromium(III) Coordination Polymers. J. Phys. Soc. Japan 2019, 88, 093708.

(17) Train, C.; Gheorghe, R.; Krstic, V.; Chamoreau, L.-M.; Ovanesyan, N. S.; Rikken, G. L. J. A.; Gruselle, M.; Verdaguer, M. Strong Magneto-Chiral Dichroism in Enantiopure Chiral Ferromagnets. Nat. Mater. 2008, 7, 729-734.

(18) Raupach, E.; Rikken, G. L. J. A.; Train, C.; Malézieux, B. Modelling of Magneto-Chiral Enantioselective Photochemistry. Chem. Phys. 2000, 261, 373-380.

(19) Atzori, M.; Breslavetz, I.; Paillot, K.; Inoue, K.; Rikken, G. L. J. A.; Train, C. A Chiral Prussian Blue Analogue Pushes Magneto-Chiral Dichroism Limits. J. Am. Chem. Soc. 2019, 141, 20022-20025.

(20) Galán-Mascarós, J. R. Bring to Light. Nat. Phys. 2015, 11, 7-8.

(21) Barron, L. D. Chirality and Magnetism Shake Hands. Nat. Mater. 2008, 7, 691-692.

(22) Rikken, G. L. J. A.; Raupach, E. Enantioselective Magnetochiral Photochemistry. Nature 2000, 405, 932-935.

(23) Barron, L. D. Chirality, Magnetism and Light. Nature 2000, 405, 895-896.

(24) Train, C.; Gruselle, M.; Verdaguer, M. The Fruitful Introduction of Chirality and Control of Absolute Configurations in Molecular Magnets. Chem. Soc. Rev. 2011, 40, 3297.

(25) Mossin, S.; Weihe, H.; Osholm Sørensen, H.; Lima, N.; Sessoli, R. Rationalisation of Weak Ferromagnetism in Manganese(III) Chains: The Relation between Structure and Ordering Phenomena. Dalt. Trans. 2004, 632-639.

(26) Sessoli, R.; Gatteschi, D.; Caneschi, A.; Novak, M. A. Magnetic Bistability in a MetalIon Cluster. Nature 1993, 365, 141-143.

(27) Coulon, C.; Miyasaka, H.; Clérac, R. Single-Chain Magnets:Theoretical Approach and Experimental Systems. Structure and Bonding 2006; 163-206.

(28) Jahn, H. A.; Teller, E. Stability of Polyatomic Molecules in Degenerate Electronic States - I-Orbital Degeneracy. Proc. R. Soc. London. Ser. A - Math. Phys. Sci. 1937, 161, 220235. 
(29) Cotton, F. A. Chemical Applications of Group Theory, 3rd editio.; John Wiley \& Sons: New York, 1990.

(30) Cole, K. S.; Cole, R. H. Dispersion and Absorption in Dielectrics I. Alternating Current Characteristics. J. Chem. Phys. 1941, 9, 341-351.

(31) Clérac, R.; Miyasaka, H.; Yamashita, M.; Coulon, C. Evidence for Single-Chain Magnet Behavior in a Mn ${ }^{\mathrm{III}}-\mathrm{Ni}^{\mathrm{II}}$ Chain Designed with High Spin Magnetic Units: A Route to High Temperature Metastable Magnets. J. Am. Chem. Soc. 2002, 124, 12837-12844.

(32) Miyasaka, H.; Madanbashi, T.; Saitoh, A.; Motokawa, N.; Ishikawa, R.; Yamashita, M.; Bahr, S.; Wernsdorfer, W. Cyano-Bridged Mn(III)-M(III) Single-Chain Magnets with $\mathrm{M}(\mathrm{III})=\mathrm{Co}(\mathrm{III}), \mathrm{Fe}(\mathrm{III}), \mathrm{Mn}(\mathrm{III})$, and Cr(III). Chem. Eur. J. 2012, 18, 3942-3954.

(33) Bałanda, M.; Tomkowicz, Z.; Haase, W.; Rams, M. Single-Chain Magnet Features in 1D [MnR4TPP][TCNE] Compounds. J. Phys. Conf. Ser. 2011, 303, 012036.

(34) Balanda, M.; Tomkowicz, Z.; Haase, W.; Rams, M. Characterization of Magnetic Ordering in Porphyrin-Based Molecular Magnets $[\mathrm{Mn}(\mathrm{R}) \mathrm{TPP}][\mathrm{TCNE}]\left(\mathrm{R}=\mathrm{OCH}_{3}, \mathrm{~F}\right.$, CN). J. Mag. Magn. Mat. 1999, 205, 14-26.

(35) Žumer, S. Pseudo-One-Dimensional Kinetic Ising Model. Phys. Rev. B 1980, 21, 12981303.

(36) Liu, B. X.; Wang, X.; Zhang, W.; Cui, P.; Gao, S. Weak Ferromagnetism and Dynamic Magnetic Behavior in a Single End-to-End Azide-Bridged Nickel(II) Chain. Adv. Mater. 2006, 18, 2852-2856.

(37) Sessoli, R. Record Hard Magnets : Glauber Dynamics Are Key. Angew. Chem. Int. Ed. 2008, 47, 5508-5510.

(38) Liu, X.; Feng, X.; Meihaus, K. R.; Meng, X.; Zhang, Y.; Li, L.; Liu, J.-L.; Pedersen, K. S.; Keller, L.; Shi, W.; Zhang, Y-Q.; Cheng, P.; Long, J. R. Coercive Fields Above 6 T in Two Cobalt(II)-Radical Chain Compounds. Angew. Chemie Int. Ed. 2020, 59, 1061010618.

(39) Caneschi, A.; Gatteschi, D.; Lalioti, N.; Sangregorio, C.; Sessoli, R.; Venturi, G.; Vindigni, A.; Rettori, A.; Pini, M. G.; Novak, M. A. Cobalt(II)-Nitronyl Nitroxide 
Chains as Molecular Magnetic Nanowires. Angew. Chemie Int. Ed. 2001, 40, 17601763.

(40) Bernot, K.; Luzon, J.; Sessoli, R.; Vindigni, A.; Thion, J.; Richeter, S.; Leclercq, D.; Larionova, J.; van der Lee, A. The Canted Antiferromagnetic Approach to Single-Chain Magnets. J. Am. Chem. Soc. 2008, 130, 1619-1627.

(41) Coulon, C.; Clérac, R.; Lecren, L.; Wernsdorfer, W.; Miyasaka, H. Glauber Dynamics in a Single-Chain Magnet: From Theory to Real Systems. Phys. Rev. B 2004, 69, 132408.

(42) Cotton, F. A.; Wilkinson, G.; Murillo, C. A.; Bochmann, M. Advanced Inorganic Chemistry, 6th Edition; 1999.

(43) Rodríuez, F.; Nuñez, P.; Marco de Lucas, M. C. Polarized Optical Absorption Spectroscopy of the $\mathrm{Tl}_{2} \mathrm{MnF}_{5} \cdot \mathrm{H}_{2} \mathrm{O}$ 1D Manganese (III) Single Crystal. J. Solid State Chem. 1994, 110, 370-383.

(44) Lever, A. B. P. Inorganic Electronic Spectroscopy; Elsevier, 1984.

(45) Tanabe, Y.; Sugano, S. On the Absorption Spectra of Complex Ions II. J. Phys. Soc. Japan 1954, 9, 766-779.

(46) Abs-Wurmbach, I.; Langer, K.; Seifert, F.; Tillmanns, E. The Crystal Chemistry of $\left(\mathrm{Mn}^{3+}, \mathrm{Fe}^{3+}\right)$-Substituted Andalusites (Viridines and Kanonaite), $\left(\mathrm{Al}_{1-\mathrm{x}-\mathrm{Y}} \mathrm{Mn}_{\mathrm{x} 3+} \mathrm{Fe}_{3+\mathrm{y}}\right)_{2}$ (O|SiO4): Crystal Structure Refinements, Mössbauer, and Polarized Optical Absorption Spectra. Zeitschrift für Krist. - Cryst. Mater. 1981, No. 1-4.

(47) Davis, T. S.; Fackler, J. P.; Weeks, M. J. Spectra of Manganese(III) Complexes. Origin of the Low-Energy Band. Inorg. Chem. 1968, 7, 1994-2002.

(48) Krzystek, J.; Telser, J.; Pardi, L. A.; Goldberg, D. P.; Hoffman, B. M.; Brunel, L.-C. High-Frequency and -Field Electron Paramagnetic Resonance of High-Spin Manganese(III) in Porphyrinic Complexes. Inorg. Chem. 1999, 38, 6121-6129.

(49) Dugad, L. B.; Behere, D. V.; Marathe, V. R.; Mitra, S. Magnetic Properties and Electronic Structure of Manganese(III) Porphyrins. Chem. Phys. Lett. 1984, 104, 353356. 
(50) Boča, R. Magnetic Parameters and Magnetic Functions in Mononuclear Complexes Beyond the Spin-Hamiltonian Formalism. In Magnetic Functions Beyond the SpinHamiltonian; Springer-Verlag: Berlin/Heidelberg, 2005; 1-264.

(51) Barra, A.-L.; Gatteschi, D.; Sessoli, R.; Abbati, G. L.; Cornia, A.; Fabretti, A. C.; Uytterhoeven, M. G. Electronic Structure of Manganese(III) Compounds from HighFrequency EPR Spectra. Angew. Chemie Int. Ed. English 1997, 36, 2329-2331.

(52) Griffith, J. S. The Theory of Transition Metal Ions; Cambridge University Press, 1961.

(53) Stephens, P. J. Theory of Magnetic Circular Dichroism. J. Chem. Phys. 1970, 52, 3489.

(54) Mason, W. R. A Practical Guide to Magnetic Circular Dichroism Spectroscopy; John Whiley \& Sons, 2006.

(55) Mossin, S.; Sørensen, H. O.; Weihe, H.; Glerup, J.; Søtofte, I. Manganese (III) Cyclam Complexes with Aqua, Iodo, Nitrito, Perchlorato and Acetic Acid/Acetato Axial Ligands. Inorganica Chim. Acta 2005, 358, 1096-1106.

(56) Bain, G. A.; Berry, J. F. Diamagnetic Corrections and Pascal's Constants. J. Chem. Educ. 2008, 85,532 .

(57) Kopnov, G.; Rikken, G. L. J. A. A Multichannel Magneto-Chiral Dichroism Spectrometer. Rev. Sci. Instrum. 2014, 85, 053106.

\section{TOC Graphic}

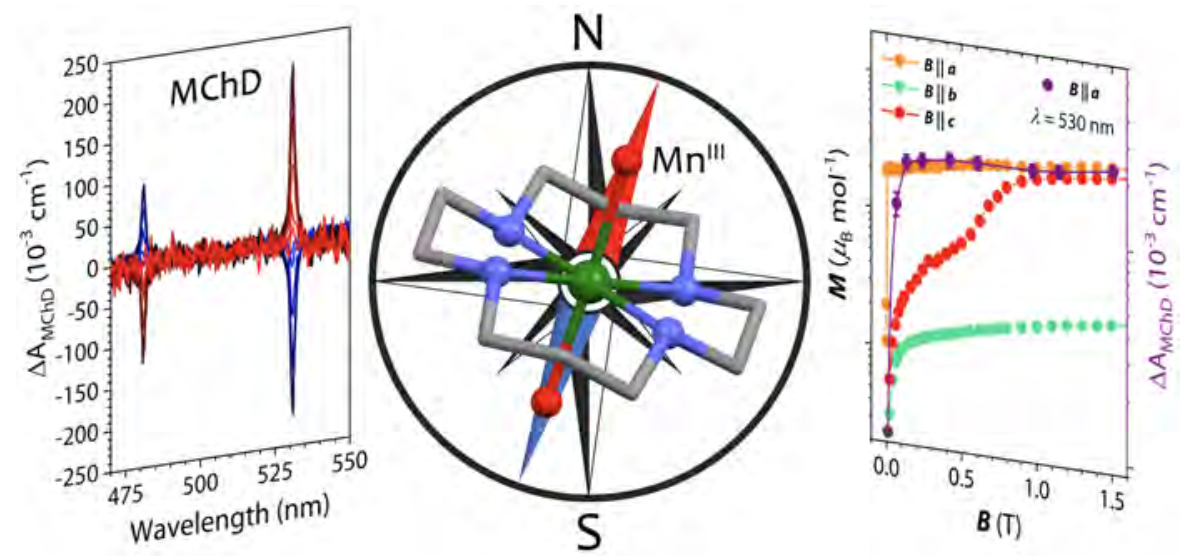

